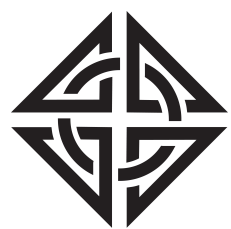

SCIENTIA

I RA N I C A
Sharif University of Technology

Scientia Iranica

Transactions C: Chemistry and Chemical Engineering

www.scientiairanica.com

\title{
Physicochemical properties and stress-strain compression behaviors of a ground tire rubber based magnetorheological elastomers
}

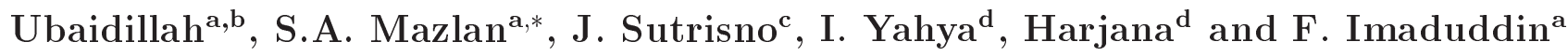 \\ a. Malaysia Japan International Institute of Technology, Universiti Teknologi Malaysia International Campus, Jalan Semarak \\ 54100, Kuala Lumpur, Malaysia. \\ b. Department of Mechanical Engineering, Faculty of Engineering, Universitas Sebelas Maret, Jalan Ir. Sutami 36A, Kentingan, \\ Surakarta, 57126, Central Java, Indonesia. \\ c. University of Surabaya, Surabaya, 60223, East Java, Indonesia. \\ d. Department of Physics, Faculty of Mathematics and Natural Sciences, Universitas Sebelas Maret, Jalan Ir. Sutami 36A, \\ Kentingan, Surakarta, 57126, Central Java, Indonesia.
}

Received 5 July 2015; received in revised form 26 February 2016; accepted 26 April 2016

\section{KEYWORDS}

Magnetorheological elastomers;

Ground tire rubber;

Electronic waste;

Magnetite powders;

Compression mode.

\begin{abstract}
This study reports a reclamation method of Ground Tire Rubber (GTR) and electronic wastes into a tunable stiffness composite, namely magnetorheological elastomers (MREs). The composite matrix was the GTR that had been separated from its metals and yarns. Meanwhile, the fillers were fabricated from magnetic cores of the Cathode Ray Tubes (CRTs) monitor waste through high energy ball milling in wet condition. Some physicochemical characterizations of the powders were initially conducted to collect the physical and chemical properties. Based on the examination, the ground powders were identified as pure magnetite $\left(\mathrm{Fe}_{3} \mathrm{O}_{4}\right)$ having low remnant and high magnetization. The MREs samples were prepared by high-temperature high-pressure sintering. The mixed of crumb rubber and magnetite powder was vulcanized under simultaneous pressure and temperature in the absence of magnetic fields, which resulted in an isotropic MREs type. The abilities of specimens were examined in relation to the external magnetic field through static and dynamic compression tests. The experimental investigation showed that the static and dynamic stresses of the stiffness increased by the increment of magnetic fields up to a particular point of flux density. The tunability of the stiffness indicated that the elastomers could provide wide ranges of storage and loss modulus.
\end{abstract}

(C) 2016 Sharif University of Technology. All rights reserved.

\section{Introduction}

The vast development of transportation and industrial electronics is one of the key accelerators of economic growth in many developing countries. Despite its positive implications, it also provides negative excess in hazardous waste growth, especially in developing countries. In the transportation sector, discarded tire

*. Corresponding author. Tel.: +60172137652

E-mail address: amri.kl@utm.my (S.A. Mazlan) is the major contributor of hazardous wastes due to the difficult reclamation of End Life of the Tires (ELTs) [1]. The worldwide demand for tires is predicted to rise about $4.2 \%$, annually, through 2015 . For instance, the European Tire and Rubber Manufacturer Association (ETRMA) reported that in 2012-2013, the amount of produced tires was about 4.6 million tones [2]. According to the Indonesian Tire Manufacturer Association (APBI), the total 4-wheeler tire market posted robust volume growth of $12 \%$ in 2013 , as 19.6 million 4wheeler tires were sold compared to 17.5 million in 
2012. Meanwhile, the 2-wheeler tire market even grew stronger as 2-wheeler tire sales volumes reached 52.3 million tires in 2013 compared to 45.6 million tires in 2012 , i.e. $15 \%$ increase [3].

The primary concern about the rapid growth of waste tire is due to its hazardous contents [4]. Significant attention is given to managing waste tire or more general hazardous waste based on three main ideas, i.e. reuse, recovery, and recycle [5]. The implementation of reusing waste tire lies in the utilization of ELTs for the same purposes as their original function, i.e. tire retreading. Tire retreading is indeed profitable due to its low cost. However, a vehicle with retreaded tire tends to take part in road accidents and collision [6]. Meanwhile, recovery is more around capturing another potential use of waste tire elements. Recovery is classified into materials and energy recoveries. The recovery of the functional elements from the waste tire includes zinc [7], carbon-carbon nanotubes [8,9], and heavy metals [10]. Meanwhile, the energy recovery is realized by utilizing waste tire for clinker burning [11] and liquefied fuel through pyrolysis [12]. Direct burning of the waste tire in the world has reached nearly $30 \%$ of the total waste [13]. Burning tire for energy recovery poses a serious problem to community health and precipitates environmental degradation (air pollution) due to its toxic gasses, e.g. $\mathrm{CO}, \mathrm{SO}_{2}$, and $\mathrm{NO}_{2}$, as well as mono- and Poly-Aromatic Hydrocarbons (PAH) $[14,15]$.

Recycling of the waste tire includes re-processing tire rubber into another functional objects rather than dumping it in the landfills, ocean dumping, or underground storage. Recycling process of tire rubber has been reported in another article, in which the so-called tire reclamation is preferable to disposal storage options due to the harmful effect on soils and underground water [16]. The reclamation of tire rubber is typically conducted by shredding it into powder form (with 2-3 mm of diameter) through either cryogenic or room temperature grindings. The ground tire is then separated from its textiles and metals using electrostatic and magnetic methods. The pure Ground Tire Rubber (GTR) can further be used as composite material for either virgin rubber filler [13] or civil purposes such as buildings, roads, concrete filler, and pavements. In-building applications of GTRbased composite are focused on sound insulation and absorption and it is realized in the composite board for room partition, particle boards, or floor parquets. Meanwhile, crumb rubber has been used for concrete mixture/reinforcement [17] and asphalt/cement pavements [18].

Likewise, electronic waste (E-waste) seizes attention of policy makers and researchers as its generation exceeds at least 3-5\% annually [19]. Among several kinds of E-waste, Cathode Ray Tubes (CRTs) monitor from obsolete PC and television is one of the major contributors to hazardous materials. The CRTs waste has become a worldwide ecological problem due to its potential hazardous contents, primarily lead, arsenic, cadmium, copper, and mercury, if inappropriately managed [20]. The problem of CRTs monitor waste management often rises in developing countries as the people start to migrate from conventional to modern lifestyle. As a developing country in which the amount of daily E-waste is predicted to be 1.2 tons, Indonesia has released policies for improving its management based on reuse, recovery, and recycle.

In Indonesia, scavengers grab the business opportunity of the CRTs monitor waste due to the value of the recovered components. The flow of the CRTs monitor wastes, as commonly done by the scavengers, is depicted in Figure 1. Most of the primary components in CRTs monitors, except deflection yoke (see Figure 2), can be recovered through the smelting process to obtain plastic, glass, and other valuable metals. The recovered materials can be utilized for glassware, aluminum utensils, iron crafts, copper crafts, and plastic equipment [19,21]. However, only the copper wire of the deflection yoke is taken in disposing of the magnetic core inside, whereas the core consists

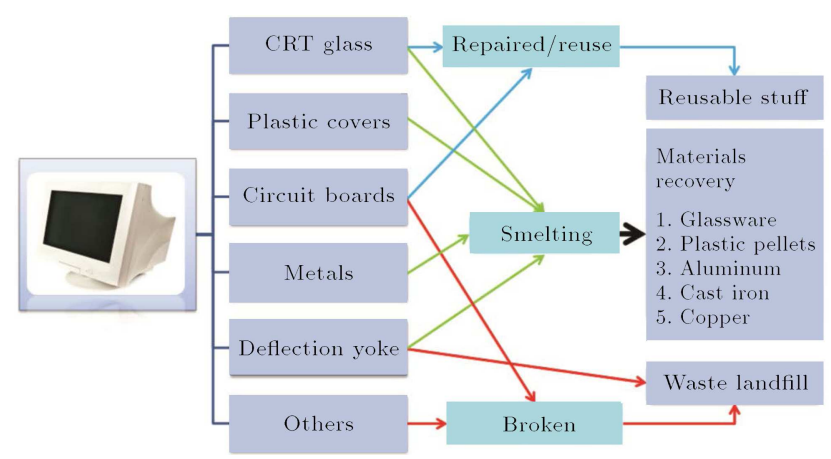

Figure 1. The flow of CRTs monitors wastes in Indonesia.

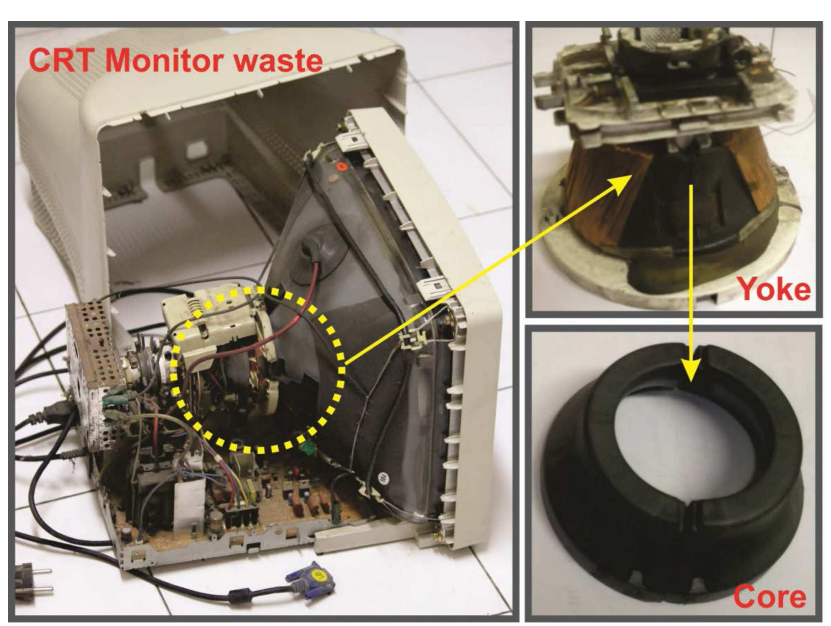

Figure 2. CRTs monitor waste as raw material for magnetite powder. 
of elements which have good magnetic properties and belong to soft magnetic materials.

The previous investigation on the use of hundred percent purely recycled rubbers to produce new components is very limited [22-25]. Consequently, the resulted product from rubber waste reclamation does not have high economic value and has limited functional uses. This study intends to provide an alternative reclamation of crumb rubber and magnetic core of the deflection yoke into a kind of smart composite, namely magnetorheological elastomers (MREs).

MREs represent intelligent elastomers whose intrinsic properties can be altered by applying a certain amount of external magnetic fields [26,27]. Unlike flexible permanent magnet, this controllable elastomer only reacts when it is subjected to the magnetic fields. The controllable properties is indicated by reversible changing of complex modulus due to the presence of magnetic fields. The intrinsic properties alteration is reversible in less than $10 \mathrm{~ms}$. The phenomenon happens since MREs are constructed of elastomeric matrix carrying magnetizable particles spread thoroughly. The arrangement of the magnetizable particle can be either random (isotropic MREs) or chainlike structure (anisotropic MREs) [26]. This unique characteristic has attracted researchers to implement MREs in the wide-range application of noise and vibration reductions, sensors, and other magnetically activated actuators. Typical applications in vibration absorber are variable stiffness bushing [28,29], propeller shaft [30], variable spring rate [31], and prosthetic leg [32]. MREs have also been introduced for sensory use, such as tire pressure control [33] and MEMS [34]. Meanwhile, the applications in active actuator are releasable attachment [35] and active morphing composites [36,37].

Ubaidillah et al. [38] have developed a map of MREs matrix and magnetizable particles in which the commonly used matrix materials are classified into saturated elastomers, unsaturated elastomers, and thermoset-thermoplastic. Most of the researchers use saturated elastomers, i.e. Room-Temperature Vulcanization (RTV) silicone, due to the easiness in the fabrication process, especially for anisotropic MREs. Meanwhile, the unsaturated elastomers are less interesting since they need longer fabrication processes and more various devices involved. To date, the utilized unsaturated elastomers have been natural rubber [39-41] and synthetic rubber, i.e. styrene butadiene rubber [42], chloroprene rubber (CIIR) [43], Bromo butyl rubber (BIIR) [44], isobutylene-isoprene [39], cispolyisoprene [45], cis-polybutadiene [27,46-50], acrylonitrile rubber [51-54], and ethylene-propylene rubber [53,54]. The magnetizable particles used for MREs are commonly provided by well-known chemical companies such as BASF (carbonyl iron, spherical shape, 1-20 microns) [52,55-57], ISP (carbonyl iron, spherical) [40,58-60], Hoganas (iron powder, irregular shape above 20 micron) [61,62], and Sigma-Aldrich (carbonyl iron/iron pentacarbonyl) [63-65]. Based on the MREs raw materials mapping, it can be inferred that the entire MREs specimens proposed since 1996 have utilized rubber compound and commercial iron particles.

This technical report offers a new class of MREs based on waste tire rubber as matrix and magnetite powders $\left(\mathrm{Fe}_{3} \mathrm{O}_{4}\right)$ from magnetic core of CRTs monitor waste. The main challenge here is reclaiming $100 \%$ vulcanized rubber without additional virgin rubber. The $100 \%$ vulcanized rubber is classified into thermoset materials that are commonly un-recycled. This classification is because the fully vulcanized rubber forms three-dimensional cross-linked network structure that contains cyclic and mono-, di-, and poly-sulfides linkages [13]. According to Tobolsky et al. [66], sulfidic bound can easily be sliced by applying high levels of pressure and temperature at the same time. Preparation of the MREs in this paper is conducted by applying simultaneous high temperature and high pressure for breaking and rendering sulfidic bound between crumb rubber and magnetizable particle. In this paper, the method used for the MREs preparation will be further named the High-Pressure High-Temperature (HPHT) vulcanization. The resulted MREs are of isotropic type since there is no application of magnetic flux during vulcanization. The behaviors of the MREs are examined through several physicochemical tests; also, their tunability is observed through static and dynamic compression loadings. The durability of the waste based MREs will be investigated in another work sequence. However, this report also explains briefly the durability based on the previous works that have investigated the stability and degradation of reclaimed ground tire rubber as well as filled elastomers.

\section{Materials and preparation}

\subsection{Characteristics of raw materials}

The crumb rubber was supplied by PT. Bengawan Sumber Baru, Indonesia, in powder form with undefined sieve. The crumb rubber has been separated from all metals and textiles. The GTR was initially screened using mesh 60 sieves. Meanwhile, the strained GTR was shredded using custom-made rubber grinder equipped with the same size sieves. Since there is no exact information from the manufacturer about types of rubber, the GTR is assumed to be comprising of synthetic and natural rubber. However, the chemical properties of crumb rubber given by the manufacturer include: acetone extract $7 \%$, ash content $5.4 \%$, carbon black $32.9 \%$, and hydrocarbon rubber $54.6 \%$.

The magnetizable powders were synthesized using 
high-energy ball mill. As a start, the deflection yoke that had been dismantled from broken CRTs was separated from its copper wires and bracket from the core (see Figure 2). One kilogram of core waste was crushed using a hydraulic press in wet condition (ethanol immersion) until passing mesh 60 sieves. The ethanol was chosen in order to avoid chemical reaction during particle crushing. The passed powders were then milled using high-energy ball mill with an angular velocity of $500 \mathrm{rpm}$. High-energy ball mill has been widely used to produce ultrafine particles even in a nano range [67]. This mechanical milling or mechanochemistry method is capable of fabricating solid-solid, solid-liquid, and solid-gases reactions that do not usually happen at ambient temperature and is feasible for large-scale implementation [68]. Since the mass ratio of powder to ball mill was $1: 10$, in this work, $50 \mathrm{~g}$ of powders was milled or ground by $500 \mathrm{~g}$ of hardened steel ball in $50 \mathrm{ml}$ of ethanol for an hour. The ground powders were dried at $70^{\circ} \mathrm{C}$ for an hour.

The physicochemical properties of iron powders were examined to determine the exact type, average size, morphology, and magnetic property of the chemical compounds. The physicochemical tests elaborated Particle Size Analyzer (PSA), Scanning Electron Microscopy (SEM), X-Ray Diffraction (XRD), Fourier Transform Infrared (FTIR), and Vibrating Sample Magnetometer (VSM). The Particle Size Distribution (PSD) of ground iron powders was conducted using SALD-2300, Shimadzu Scientific Instruments. The size distribution, as depicted in Figure 3, was: $d_{10}=$ $6.517 \mu \mathrm{m}, d_{50}=16.919 \mu \mathrm{m}$, and $d_{90}=44.142 \mu \mathrm{m}$.

The microstructure observation was undertaken using FEI-Inspect operated at $10 \mathrm{kV}$. The examination of iron powders phase involved X-ray diffraction analysis using the $\theta-2 \theta$ method in which the $\mathrm{X}$ ray diffractograms were recorded in the range of $2 \theta$ from $10^{\circ}$ to $80^{\circ}$. XRD-PHILLIP XPERT PRO was equipped with $\mathrm{Cu} K_{\alpha 1}$ radiation $(\lambda=1.54205 \AA)$. The infrared spectra were logged in $2 \mathrm{~cm}^{-1}$ scan step and range vibration of $500-4000 \mathrm{~cm}^{-1}$ by utilizing Cary

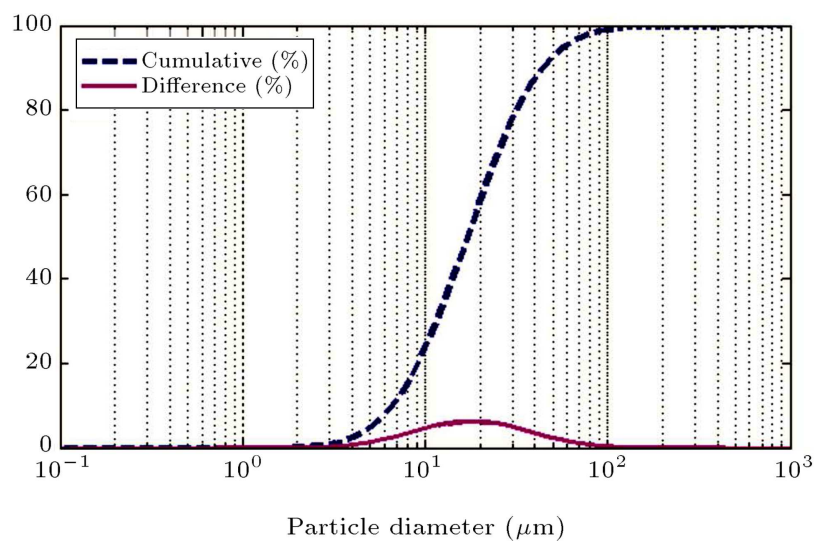

Figure 3. Particle size distribution of magnetite powder.
600 Series, Agilent Technologies Fourier Transform Infrared (resolution of $4 \mathrm{~cm}^{-1}$ ). In the experiment, the iron powders were mixed and pressed with Potassium Bromide $\mathrm{KBr}$ medium into a thin film. Meanwhile, the magnetic characterization was carried out using lake shore Vibrating Sample Magnetometry (VSM). The experimental curves were measured at ambient temperature after applying a maximum field intensity of 1 Tesla.

The micrograph obtained by SEM evaluation for iron powders is shown in Figure 4(a). The particles have a narrow distribution where the size is within 0.5-25 microns according to the scale. The shape of particles is irregular; it is one of the main disadvantages of mechanical milling technique in which the operators cannot control the powder shapes. Therefore, the particle should be feasible for the purpose of MREs. The XRD pattern of the magnetic core powders is shown in Figure 4(b). Based on JCPDS card no. 19-0629,

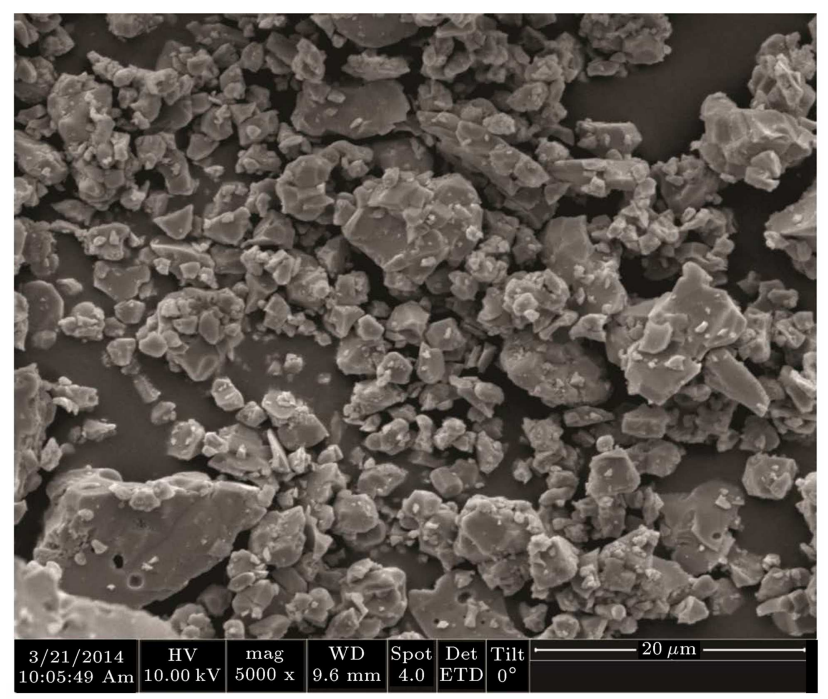

(a)

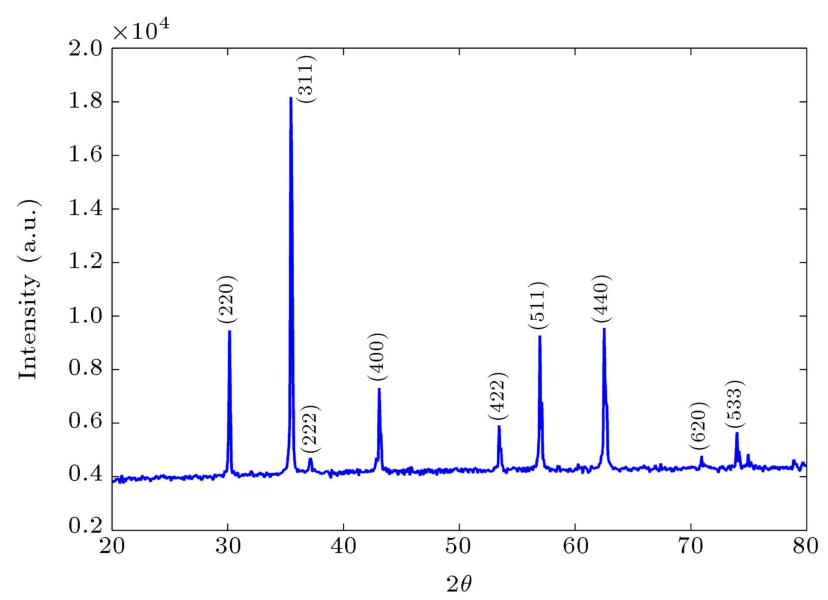

(b)

Figure 4. (a) SEM image. (b) XRD patterns of the ground magnetizable particle. 
the XRD pattern of sample E-waste powders portrays magnetite $\left(\mathrm{Fe}_{3} \mathrm{O}_{4}\right)$ phase with nine characteristic peaks at $30.1^{\circ}, 35.4^{\circ}, 37.1^{\circ}, 43.1^{\circ}, 53.4^{\circ}, 56.9^{\circ}, 62.5^{\circ}, 70.9^{\circ}$, and $73.9^{\circ}$. The peaks correspond to $(220)$, (311), (222), (400), (422), (511), (440), (620), and (533). The diffraction peaks of iron powder can be indexed to an inverse spinel structure of $\mathrm{Fe}_{3} \mathrm{O}_{4}$ particles [69].

Besides the XRD test, FTIR spectroscopy was used to confirm the chemical compound of the magnetite powders. The FTIR transmittance spectrum of magnetite is presented in Figure 5(a). Many studies confirmed that the magnetite compound shows bands associated with vibration torsion $(v t)$ and stretching (vs) modes of $\mathrm{Fe}-\mathrm{O}$ with respect to octahedral and tetrahedral sites. The FTIR spectrum of the magnetite corresponds to $568.9 \mathrm{~cm}^{-1}$ and $487.9 \mathrm{~cm}^{-1}$. The peaks match the magnetite peaks explored in some previous studies in characteristic [68,70,71].

The magnetic property of the well-prepared magnetite is measured at room temperature $(300 \mathrm{~K})$ using VSM from - 1 to 1 Tesla or $-10,000$ to 10,000 Gauss field intensity. Figure 5(b) shows the hysteresis loops of the samples that indicate a reversible characteristic with narrow hysteresis loops. The behavior illustrates that the magnetite powders belong to superparamagnetic at ambient temperature. According to Morel and coworkers [70], the material presents superparamag-

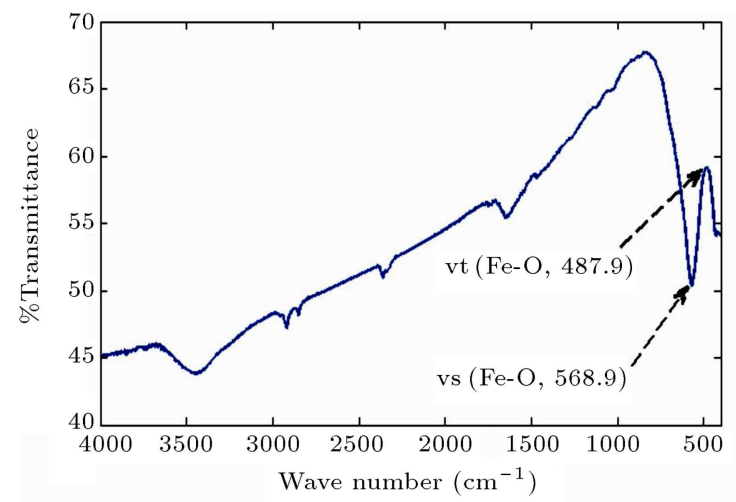

(a)

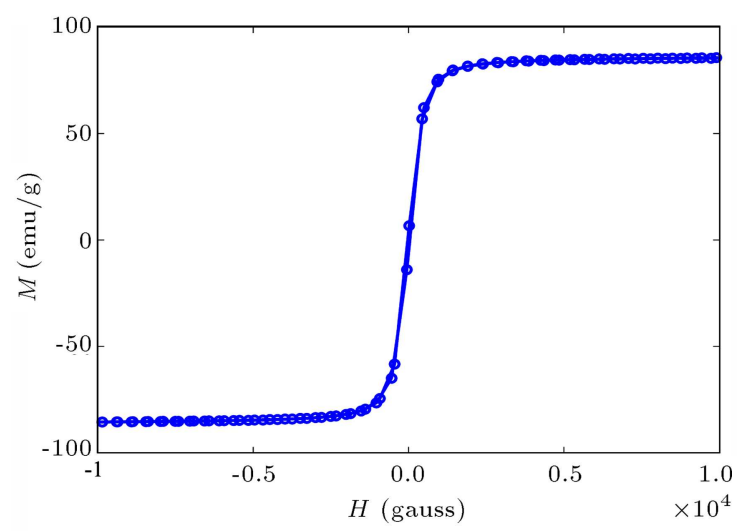

(b)

Figure 5. (a) FTIR spectrum. (b) Magnetic property. netic behavior when the normalized remanence is about 0.01 or less. The magnetic saturation value of the magnetite powders is $92.9 \mathrm{emu} / \mathrm{g}$. Although the value is lower than that of commercial carbonyl iron (above $100 \mathrm{emu} / \mathrm{g}$ ), E-waste magnetite powders still can be considered for replacing commercial carbonyl iron or another iron powder.

\subsection{Sample preparation}

The fabrication of waste based MREs consists of two major steps: mixing and reclaiming. Since the expected type of MREs is isotropic, electromagnetic treatment was not required before vulcanization. A mechanical mixer was utilized for mixing crumb rubber and magnetite powders at $250 \mathrm{rpm}$. Unlike other rubber compound based matrices, the mixing can be easily accomplished and it achieves homogeneous mix fast as all the raw materials are in powder form. The mixing time was about 5-10 minutes for 10 grams of mass per sample, and the homogenity of the mixture could be verified visually. The homogeneous mixtures were then poured into a steel mold having diameter of chamber molding of $30 \mathrm{~mm}$. The molding was then mounted in the HPHT devices as shown in Figure 6. The HPHT equipment is constructed from several parts such as hydraulic unit, heater controller, and heater element. The sintering of MREs specimen was performed by firstly applying pressure of $10 \mathrm{MPa}$ to the molding and then generating heat by $200^{\circ} \mathrm{C}$. The heating rate was about $10^{\circ} \mathrm{C} / \mathrm{min}$, which was the maximum capability of heater controller in regulating power. During sample preparation, the initial temperature was

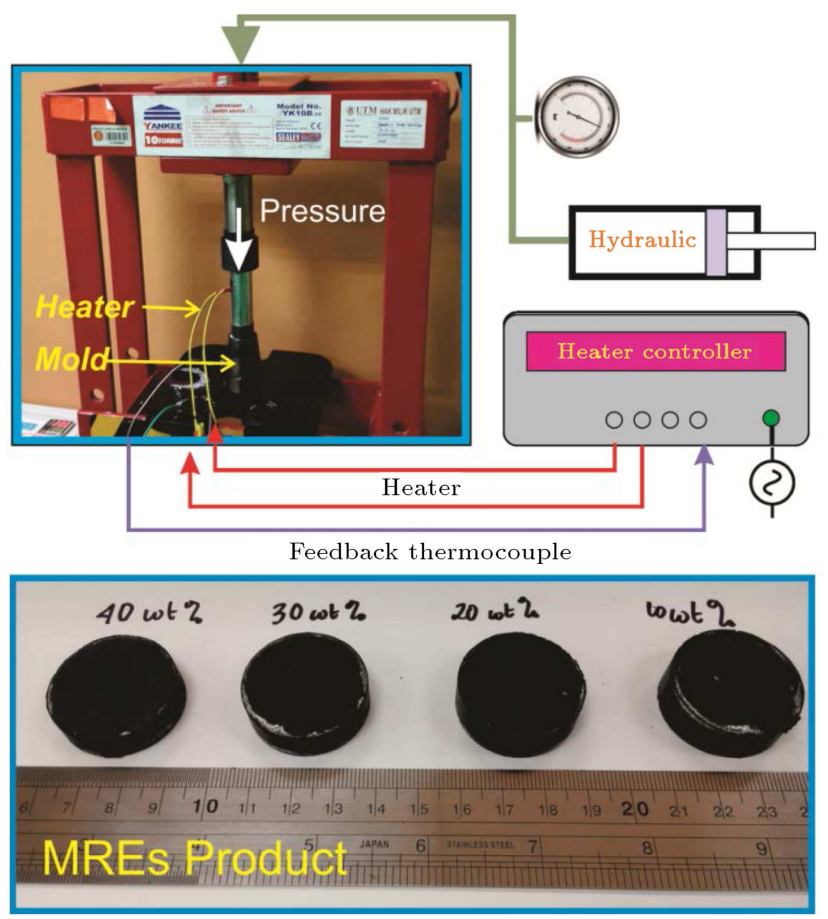

Figure 6. The apparatus and MREs specimens. 
about $25^{\circ} \mathrm{C}$ to $27^{\circ} \mathrm{C}$ (room temperature) transiently increasing until $200^{\circ} \mathrm{C}$ for $17-20$ minutes. After steady state temperature, the heater controller maintained supplying electric current to the heater elements based on the temperature set point. This step was kept for an hour. The hot mold was then allowed to cool down until reaching ambient temperature.

The weight fraction of magnetite powders within a sample varied by $10 \mathrm{wt} \%, 20 \mathrm{wt} \%, 30 \mathrm{wt} \%$, and $40 \mathrm{wt} \%$. The dimensions of the obtained samples are different. They depend on the weight fraction of the magnetite powders. The higher amount of magnetite powders, the thinner and the higher density of the sample. Meanwhile, the volume fraction $\phi$ of the magnetite powder within each sample can be determined using Eq. (1):

$$
\phi=\frac{d_{\mathrm{MREs}}-d_{W}}{d_{M P}-d_{W}},
$$

where $d_{\text {MREs }}$ is density of MREs, $d_{W}$ is density of pure waste rubber $\left(0.47 \mathrm{~g} \mathrm{~cm}^{-3}\right)$, and $d_{M P}$ is density of magnetite powders $\left(5.8 \mathrm{~g} \mathrm{~cm}^{-3}\right)$. The calculation results of weight fractions are $0.13,0.16,0.20$, and 0.26 of volume fractions.

\section{Apparatus and experimental procedure}

An electromagnetic device was developed for supporting device in compression testing under magnetic field. It was firstly designed and its flux density profile was simulated using FEMM to predict the value of magnetic flux in magnetization area. The electromagnetic device, as shown in Figure 7(a), consists of electromagnetic wall, center core, and two sets of coils. The coils are separated into two parts: upper coil and lower coil (AWG19, total of 5400 turns), for considerations of easy placement of MREs samples and Gaussmeter measurement in the gap. A DC power supply (TTi CPX 4000, maximum current of $20 \mathrm{~A}$ ) was used to regulate current to the coil.

An observation was conducted to determine the relationship between current supplied to the coil and flux density in the specimen gap. The flux density was measured in $2.5 \mathrm{~mm}, 5 \mathrm{~mm}, 7.5 \mathrm{~mm}$, and $10 \mathrm{~mm}$ air gap distances using Hirst Magnetic Instrument GM08 Gaussmeter. Each gap was tested by applying current 0-8 A with interval of 0.25 A. Figure $7(\mathrm{~b})$ shows the amount of flux densities in different air gaps and the applied current. The developed electromagnetic device can provide high flux density of about $2500 \mathrm{mT}$ in $2.5 \mathrm{~mm}$ gap and $8 \mathrm{~A}$ of applied current. The relation between applied current and generated magnetic flux is useful to estimate magnetization treatment during the compression test. The figure also informs that the gap distance significantly influences the amount of flux density which means that in compression working mode

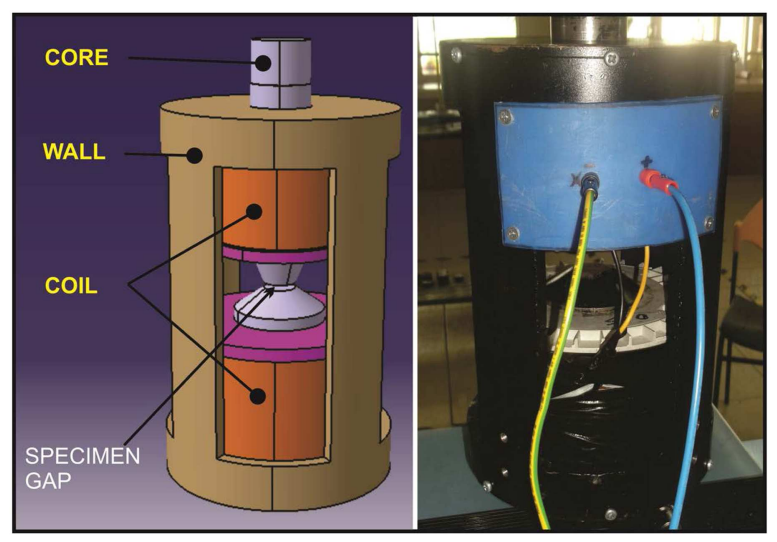

(a)

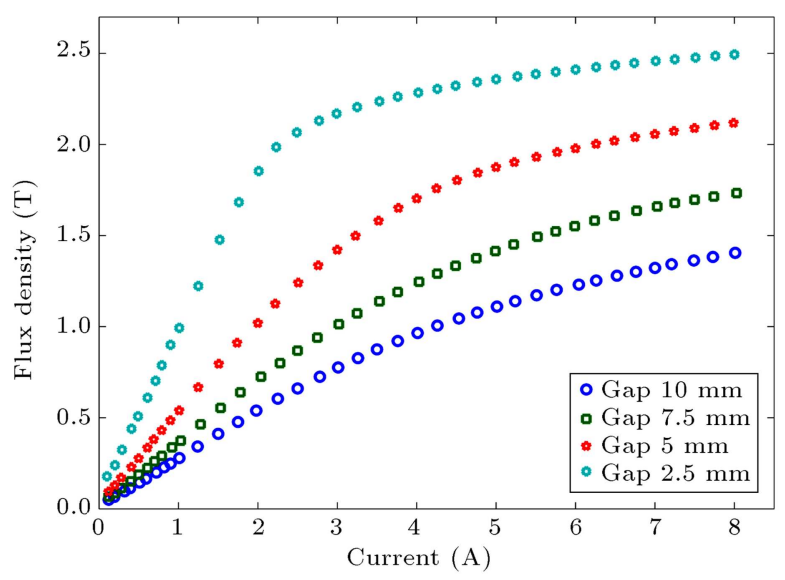

(b)

Figure 7. Electromagnetic device: (a) Apparatus; and (b) flux density within the air gap.

of MREs, the amount of flux will not remain constant in gap alterations.

Physicochemical evaluations of MREs sample were conducted through ATR-FTIR, SEM, and VSM, which use the same facilities with the magnetite powders characterizations. The ATR was performed using Agilent Diamond ATR accessories fitted in Cary 600 Series, Agilent Technologies. Here, the slice (1 mm of thickness) of MREs surface was probed on the diamond (up to 2 microns deep) by infrared energy in a particular range of wavelengths. The spectra were collected in 4 scans accumulation at $4 \mathrm{~cm}^{-1}$ of resolution over the wavelength range of $500-4000 \mathrm{~cm}^{-1}$ at room temperature. The SEM equipment was operated at $5 \mathrm{kV}$. Meanwhile, the setting parameter of VSM was similar to that of the magnetite powders test.

The intrinsic property alteration of the MREs, as response to the external magnetic field, was evaluated in static and dynamic compression. The schematic principle of compression mode in this test is illustrated in Figure 8(a). The compression mode of MREs is identical with the lumped spring elements consisting of cylindrical MREs subjected to a compression force 


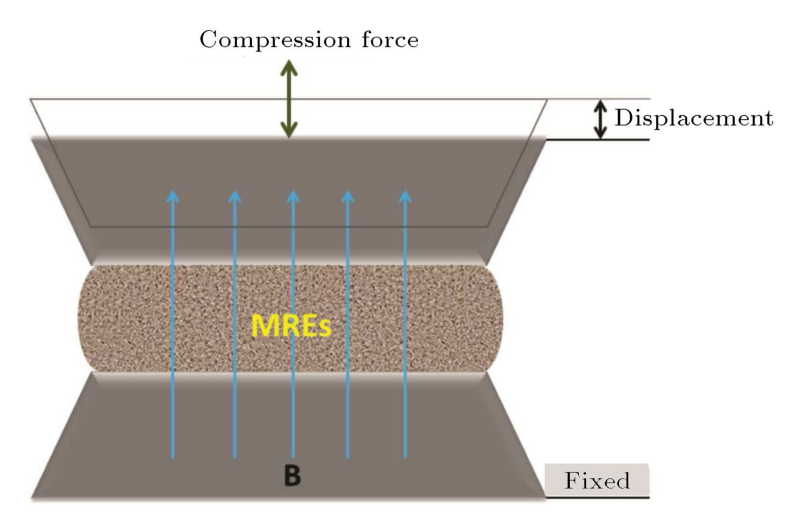

(a)

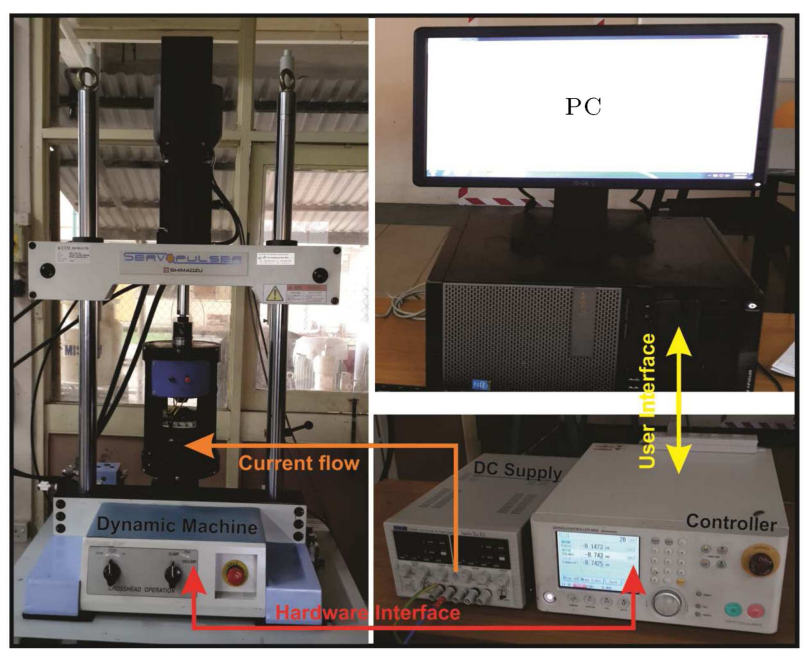

(b)

Figure 8. (a) Schematic picture of MREs in squeeze mode. (b) Compression testing setup.

in either static or dynamic values in off-state (without magnetic fields) and on-state (with magnetic fields application). Shimadzu ServoPulser EHF-L Series, as shown in Figure 8(b), was used to perform the compression test with maximum force of $\pm 20 \mathrm{kN}$ and functional excitation frequency range 0.1 up to $50 \mathrm{~Hz}$, depending on the excitation amplitude (10 to $0.9 \mathrm{~mm}$, respectively). The Shimadzu Servo Controller 4830 is equipped with user interface software that is able to process force and displacement data in the time domain becomes force versus displacement curves. The specimen dimension inputted in the software is useful for determining stress-strain relationship.

The static loading of MREs was performed by applying ramp force with controllable crosshead speed of $12 \mathrm{~mm} / \mathrm{min}$ (ASTM D575-91). The maximum compression strain was set to be $25 \%$ of the specimen thickness. The dynamic compression tests were performed at $1 \mathrm{~Hz}$ of excitation frequency and $20 \%$ of strain amplitude. The strain amplitude was controlled according to cyclic equation of $\gamma=\gamma_{a} \sin (2 \pi f t)$, where $\gamma_{a}$ is strain amplitude and $f$ is excitation frequency. The MREs specimens were subjected to

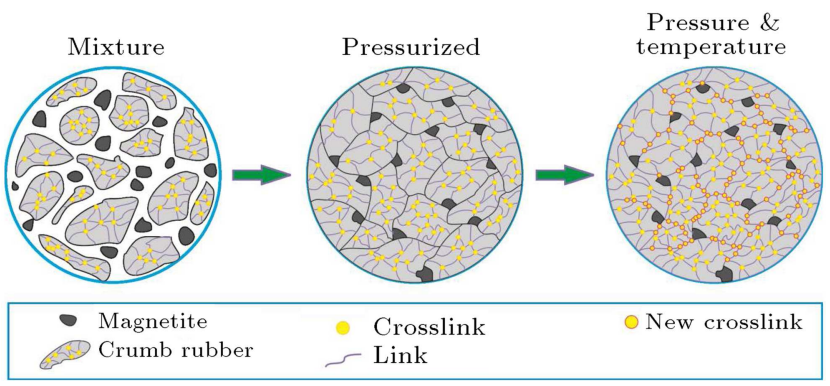

Figure 9. Sketch of rubber vulcanization in MREs fabrication process.

harmonic loading which fluctuated about mean level (half of strain amplitude). During compression test, the on-state currents from DC power supply varied from 0 to $6 \mathrm{~A}$ by interval of $1 \mathrm{~A}$. The temperature of electromagnetic core, which directly contacted the sample, was monitored during the current drained to the coil. The temperature was kept below $60^{\circ} \mathrm{C}$ to maintain the condition of the specimen.

\section{Results and discussion}

\subsection{Mechanism of revulcanization}

The mechanism of rubber vulcanization into MREs specimen is described schematically in Figure 9. The most accepted theory to date to explain the binding mechanism among crumb rubbers is high pressuretemperature particle adhesion. The explanation was previously mentioned by Tobolsky [66] and was supported by experimental data presented by Morin et al. [23] and Bilgili et al. [25]. The pressure is subjected to removal of the gaps between particles in molding chamber. As a result, the particles contact intimately and the grain boundaries are latched tightly. The intimate grain boundaries will overcome oxidation of materials, especially magnetite powders. The high temperature adds the required energy to slice the sulfidic bonds or crosslink bonds. The increase in energy triggers chemical exchange reactions at both the powder interfaces and inside the rubber powders. This chemical exchange enables reforming of sliced sulfidic crosslink. Therefore, a fusing between rubber powders happens and it adheres the magnetite powders into a single piece. Morin et al. [23] performed hightemperature Electron Spin Resonance (ESR) measurement to prove particle adhesion phenomena in rubber reclamation. The result showed that six-fold increase was found in the peak intensity of free radical formation as the temperature was elevated to the typical molding temperature of about $200^{\circ} \mathrm{C}[22]$.

\subsection{Physicochemical properties}

Transmittance data for waste based MREs specimen in different weight percent values of magnetite powders are shown in Figure 10. The figure portrays the ATR- 
Table 1. The description of absorption peaks of MREs IR-spectra.

\begin{tabular}{ccc}
\hline $\begin{array}{c}\text { Wave number } \\
\left(\mathbf{c m}^{-1}\right)\end{array}$ & Designation and observation & $\begin{array}{c}\text { Group } \\
\text { rubber }\end{array}$ \\
\hline 2960 & $\mathrm{C}-\mathrm{H}$ symmetric stretching & CSM \\
2917 & $\mathrm{CH}_{3}$ asymmetric stretching & SBR \\
2848 & $\mathrm{CH}_{2}$ symmetrical stretching & SBR \\
1540 & $\mathrm{CH}_{2}$ asymmetric bending & $\mathrm{CSM}$ \\
1370 & $\delta\left(\mathrm{CH}_{3}\right)$ scissoring/bending vibration & NR \\
1266 & $\mathrm{CCH}$ asymmetric bending & $\mathrm{CSM}$ \\
833 & $\delta(\mathrm{C}-\mathrm{H})$ scissoring/bending vibration & NR \\
758 & $\mathrm{C}-\mathrm{H}$ out of plane deformation corresponding to monosubtituded benzene & SBR \\
699 & $\mathrm{C}-\mathrm{H}$ out of plane deformation corresponding to monosubtituded benzene & SBR \\
\hline
\end{tabular}

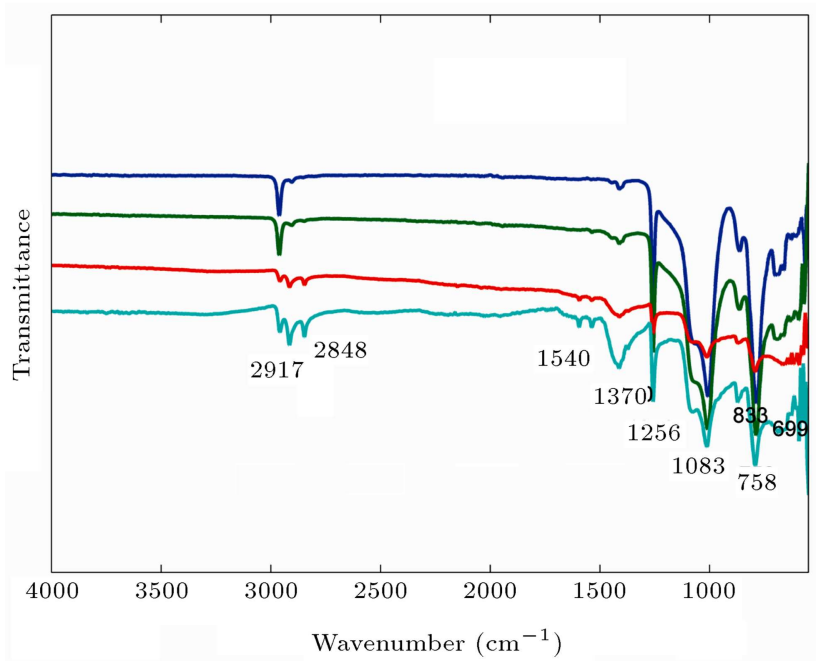

Figure 10. FTIR spectra of MREs in the range of $3400-500^{-1} \mathrm{~cm}$.

FTIR spectra of the MREs samples in $500-3400 \mathrm{~cm}^{-1}$. All spectra show similar peak characteristics between different weight fractions. The results confirm that the MREs matrix consists of several types of rubber such as Styrene-Butadiene Rubber (SBR), chlorosulphonated monomer (CSM), and Natural Rubber (NR). The presence of SBR can be noted from band characteristics of $2917 \mathrm{~cm}^{-1}, 2848 \mathrm{~cm}^{-1}, 758 \mathrm{~cm}^{-1}$, and $699 \mathrm{~cm}^{-1}$. The transmittance peaks of CSM are found out by $2960 \mathrm{~cm}^{-1}, 1540 \mathrm{~cm}^{-1}$, and $1266 \mathrm{~cm}^{-1}$. Meanwhile, the NR bands are represented by the presence of peak transmittance at $1370 \mathrm{~cm}^{-1}$ and $833 \mathrm{~cm}^{-1}$. All bands assignment can be referred and matched to the previous literature [72-74].

All peaks found in the ATR-FTIR test reflect that either stretching or bending vibrations of each compound belong to rubber hydrocarbon components. There is no outlier compound apart from rubber chemistry. However, the peak that indicates the presentation of $\mathrm{Fe}-\mathrm{O}$ does not appear in the curves. This absence is caused by the rubber hydrocarbon compounds having refractive index much higher than that

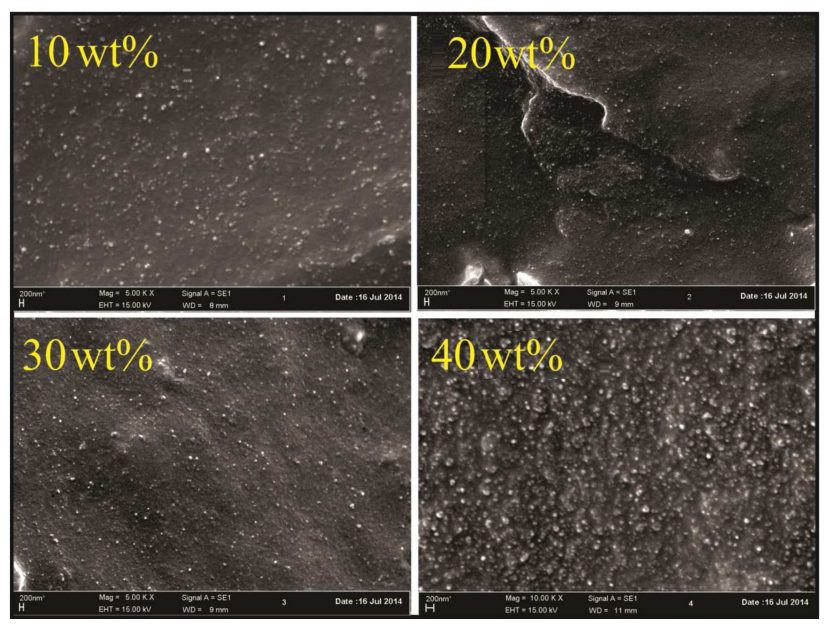

Figure 11. Microstructures of MREs with different weight percentage values of magnetite particle.

of magnetite compound. Besides that, the spectrum of magnetite is usually detected if the magnetite powders are embedded in Kalium Bromide (KBr) appropriately. Therefore, the infrared can penetrate the $\mathrm{KBr}$ and further be received by the receiver. The designations of the main peaks are listed in Table 1.

The morphologies of the cross-sectional MREs with different weight fractions of magnetite powders are depicted in Figure 11. A well-dispersed magnetite powder within MREs matrix is the primary requirement of the consistent performance in their functional behavior. A good distribution will ensure that the magnetic flux flows uniformly through the MREs. The dispersion of particles can be provided in a direct evidence by scanning electron microscopy. The isotropic type of the MREs is confirmed by homogeneous dispersion of powders in the observed area. It can be seen that the magnetite powders penetrate seriously in the matrix. The weight percent of each sample can be visually differentiated in the photographs. The MREs having higher weight fraction of magnetite powders seem to have narrower grain distance and tend to agglomerate.

The magnetic properties of the as-prepared waste 
Table 2. Magnetic properties of the MREs samples.

\begin{tabular}{ccccc}
\hline $\begin{array}{c}\text { Weight } \\
\text { fraction }\end{array}$ & $\begin{array}{c}\text { Density } \\
(\mathrm{g} / \mathbf{m l})\end{array}$ & $\begin{array}{c}\text { Coercivity } \\
(\mathbf{G})\end{array}$ & $\begin{array}{c}\text { Magnetization } \\
(\mathbf{e m u} / \mathrm{g})\end{array}$ & $\begin{array}{c}\text { Retentivity } \\
(\mathbf{e m u} / \mathrm{g})\end{array}$ \\
\hline $10 \mathrm{wt} \%$ & 1.204 & 40.659 & 7.2161 & 0.1064 \\
$20 \mathrm{wt \%}$ & 1.351 & 42.164 & 15.185 & 0.3002 \\
$30 \mathrm{wt} \%$ & 1.550 & 43.207 & 20.723 & 0.5631 \\
$40 \mathrm{wt} \%$ & 1.828 & 43.594 & 27.709 & 1.4753 \\
\hline
\end{tabular}

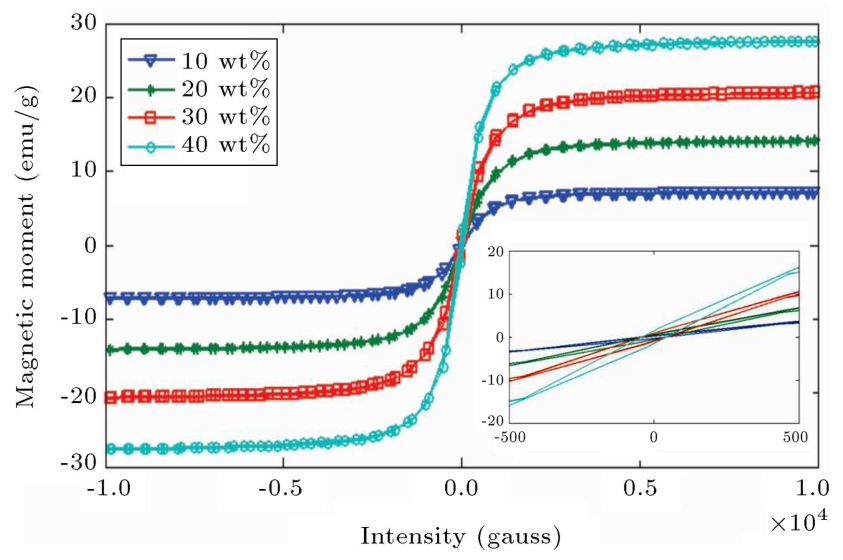

Figure 12. Magnetic properties of MREs with different weight percentage values of magnetizable particles.

based MREs with various weight fractions of magnetite powders are portrayed in Figure 12. The hysteresis curves represent $\mathrm{M}-\mathrm{H}$ relationship, in which the hysteresis loops are enlarged in particular ranges. The saturation point of the MREs is much lower than the magnetic saturation of pure magnetite powders. The magnetization decreases with the decrease in weight fraction of magnetite powders. The VSM results are useful for understanding the basic coefficients of magnetic material, such as magnetic saturation, coercivity, magnetization, and retentivity, as summarized in Table 2. The B-H (field density vs field intensity) relationship of each sample can also be derived based on the $\mathrm{M}-\mathrm{H}$ curves and the coefficients. The $\mathrm{M}-\mathrm{H}$ (volume magnetization vs field intensity) relationship also infers the magnetic permeability $\mu$ of the MREs. In the design of magnetorheological devices, the $\mathrm{B}-\mathrm{H}$ relationship is employed in finite-element modeling of the magnetic circuit. Therefore, the flux density of the MREs element in the instrument can be initially estimated. The magnetization curves with various weight fractions of magnetite powders start with a slope that indicates initial magnetic permeability. The magnetic permeability of the MREs will increase with the rise in magnetic particle. However, it is always less than the permeability of pure magnetite powders.

\subsection{Mechanical properties}

Since 1996, the mechanical behaviors of the MREs have been accomplished by many researchers focusing on shear property under external magnetic fields induction. According to this shear property, the obtained parameters, i.e. shear modulus, loss modulus, and loss tangent, can further be used in design consideration of some MR materials based devices. However, in shear mode, the MREs need suitable bonding agent to unite shear plate and sample. The bonding agent should have higher limits than the MREs maximum shearing deformation. The compression mode is appropriate for high load application, for instance, seismic bearing, since this device should bear higher vertical load than shear load.

The stress-strain relationship of MREs under compressive loadings is useful in future determination of the functional behavior. The most common property that figures the ability of MREs in responding to the external magnetic field is MR effect. The MR effect, as stated in Eq. (2), can be recognized as the fraction of the difference between on-state and off-state respond parameters to the off-state respond parameter [38]. In practice, the parameters can be forces [56], normal stress [75], stiffness [76], shear stress, and dissipation energy [77]. In this study, the MR effect in static and dynamic testing conditions can be determined through both static and dynamic compressive stresses.

$$
\text { MR Effect }=\left|\frac{\text { value }_{\text {on state }}-\text { value }_{\text {off state }}}{\text { value }_{\text {off state }}}\right| \times 100 \% \text {. }
$$

Figure 13(a) to (d) show the stress-strain relationship in response to static loading for $10 \mathrm{wt} \%, 20 \mathrm{wt} \%$, $30 \mathrm{wt} \%$, and $40 \mathrm{wt} \%$, respectively. The curves show ramp trend since the applied static loading is also in ramp function. The off-state responses in all weight fractions form single gradient of the curve that means the change of stress values is purely influenced by basic properties of the rubber composite. When the current is applied to energize the MREs, the value of stress maintains to increase, as indicated by higher gradient, and in a particular strain, the stress slowly increases. Interaction between magnetic particles causes higher gradient in response of the first stage as a reaction to the flux densities across the sample. Gradient here represents the modulus of elasticity of the MREs. The second phase gradient is influenced by the underlying modulus of elasticity of the rubber composites, and 


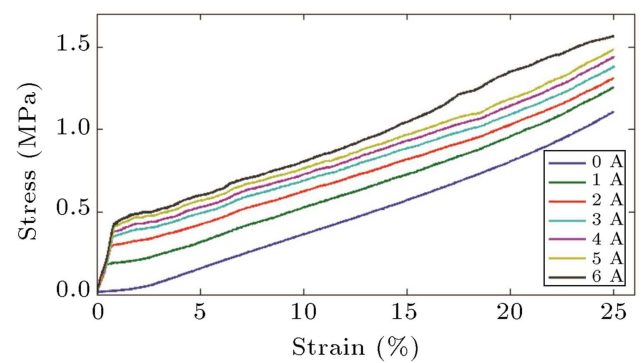

(a)

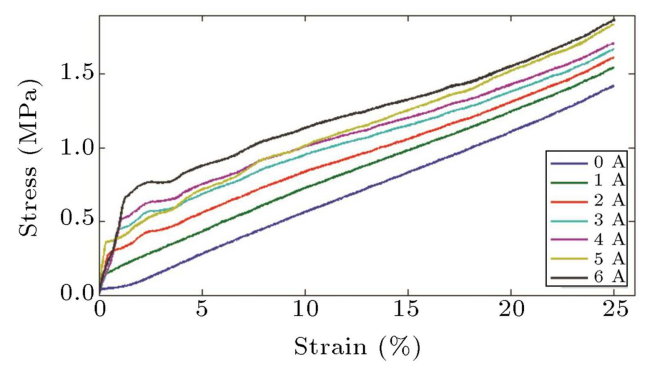

(c)

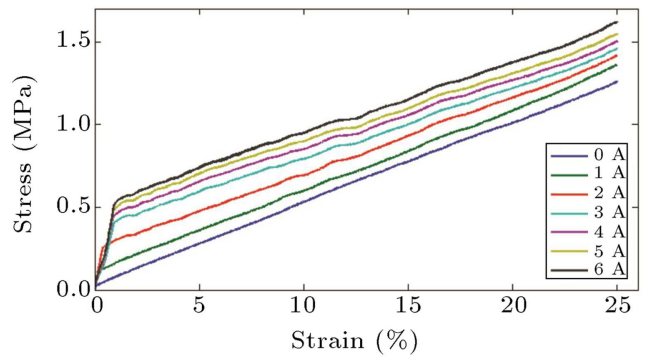

(b)

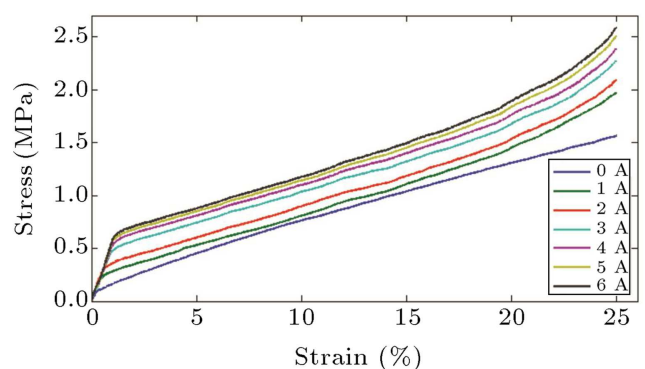

(d)

Figure 13. Stress-strain curves of MREs in static loading: (a) 10 wt\%; (b) $20 \mathrm{wt} \%$; (c) 30 wt\%; and (d) 40 wt\%.

this is because the value of the gradient is nearly the same as that of the off-state response.

From a quantitative viewpoint, the amount of waste tire based MREs compressive stress is relatively high. The compression stress achieved about 2.5 MPa by the sample with $40 \mathrm{wt} \%$ magnetite, at maximum applied current of $6 \mathrm{~A}$. However, the off-state condition also shows a high-stress value for all samples. The acceptable argument is that rubber tire usually has high modulus of elasticity since it contains high amount of carbon black. Therefore, researchers often add certain amounts of carbon black to the rubber compounds to increase the off-state modulus of elasticity of the MREs [78].

Rubber based vibration absorbers work in small amplitude and wide ranges of operating frequency. Likewise, the MREs are often operated in small strain deformation in the pre-yield region of the linear viscoelastic range. The strain deformation in this study was limited to $20 \%$ due to the reason. In structural vibration isolator, the MREs are proposed to be utilized as tunable elastomeric bearing where the load belongs to a dynamic category. Therefore, this tunable isolator supports the structure under dynamic compression mode operation. The tunable mechanical properties are useful for shifting the natural frequency of the structure system so that the vibration response does not meet the disturbance frequency from the source.

The hysteresis responses of the MREs as viscoelastic materials reflect the intrinsic energy mechanism in response to the cyclic deformation. The total deformation energy can be calculated from the area (trapezoidal rule) covered by the hysteresis curve of force-displacement $(F(t)$ versus $x(t))$ as stated in Eq. (3). The intrinsic energy within viscoelastic elastomer is represented in two forms, i.e. stored energy and dissipated energy. The stored energy is usually approached by determining the storage modulus which represents the value of the stored energy during deformation. Meanwhile, the dissipated energy is denoted by the loss modulus which is defined by the amount of energy dissipated by the MREs through deformation.

$$
E=\oint F(t) d(x(t))
$$

The hysteresis curves shown in Figure 14 are a response of stress-strain in accordance with harmonic loading. Each curve has been calculated from one period of force-displacement data from 50 cycles per set experiment. The repetition of the cycle is taken to make sure that the values of force-displacement data are steady state. The hysteresis curves portrayed in the figure present the results of cyclic test under $1 \mathrm{~Hz}$ and $20 \%$ strain. The results in no external magnetic field $(H=0)$ are compared with the results at presentation of the external magnetic field. The increase in dynamic stress as the alteration of magnetic fields is clearly visible when it is compared to the lower state. As is apparent, the hysteresis loops imply a complex property of the MREs as an induced magnetic field. The hysteresis area increases in every higher state and the loops change their nature. The dynamic stress amplitude rises in a particular point of material strain that means a greater force is required to maintain the deformation of MREs at the equivalent level of strain. The complex shape 


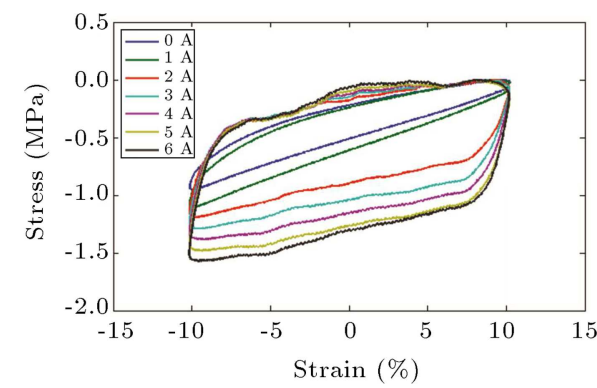

(a)

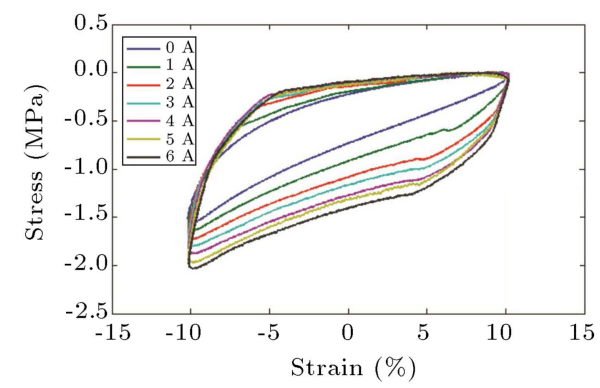

(c)

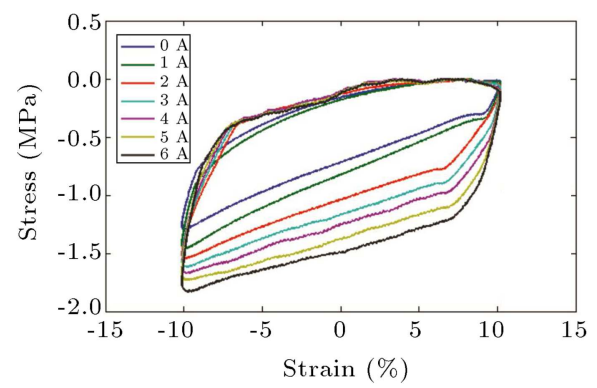

(b)

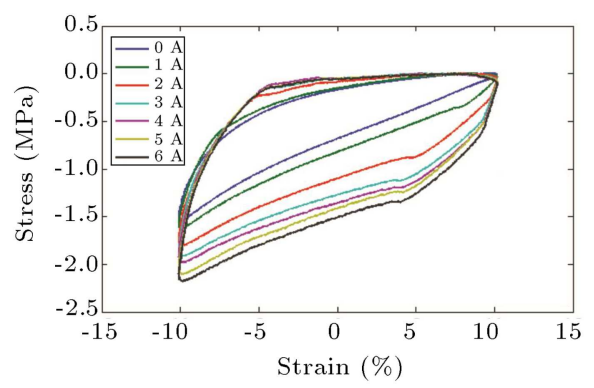

(d)

Figure 14. Stress-strain curves of MREs in dynamic loading: (a) 10 wt\%; (b) 20 wt\%; (c) 30 wt\%; and (d) 40 wt\%.

of hysteresis curves needs further viscoelastic analysis to reveal the dynamic properties of the samples.

\subsection{Durability consideration}

The primary requirement for the implementation of reclaimed waste tire rubber is that the rubber should assure the durability and life span. The requirement should also be appointed to the MREs based devices, such as adaptive tunable vibration absorber, since they are constructed of soft (elastomeric matrix) and hard materials (magnetizable powder). Most of the devices are implemented in fluctuate loads and environment changing in long time span. The stability and degradation of the MREs must be the primary consideration due to those operating conditions. Thermal analyses such as Differential Scanning Calorimetry (DSC), thermogravimetric analysis (TGA/DTA), Dynamic Mechanical-Thermal Analysis (DMTA), aging test, thermal oxidation, and UV oxidation are usually conducted to investigate the performance of the elastomeric materials including MREs as their response to thermal loads. The studies on thermal ans of the MREs based on virgin rubber and/or saturated elastomers can be found in some previous works $[27,41,57,79-82]$. However, since the specimens studied in this report are made of waste rubber as the MREs matrix, there is no report that precisely explains their stability and degradation. The broad investigation on the thermal analyses of the waste rubber based MREs will be presented in the other future report.

In the approach for predicting durability of the waste rubber based MREs, the thermal analysis of the reclaimed waste rubber can be preliminarily referred. The investigation on the durability of waste rubber, especially ground tire rubber, can be explored in some previous reports. The thermal analyses of the reclaimed tire rubber waste without mixing with virgin rubber have been investigated by some researchers [8385]. In the investigation, the method for compounding crumb rubber utilizes screw mixer in the temperature of $180^{\circ} \mathrm{C}$ with additional vulcanization agents such as zinc, sulfur, and stearic acid. The difference with the method performed by Morrin et al. (2002) [23] is that the pressure is much less than the pressure applied in HTHP process. In the work performed by $\mathrm{De}$ et al. (2006) [83], the reclaimed tire rubber remains having good tensile and hardness properties. Even by additional concentration of TMTD, the phenomenon showed the anti-aging characteristics of the reclaimed rubber. The results were also compared to the thermal characteristics of the virgin natural rubber. Formela et al. (2014) [84] investigated the thermomechanical reclaiming process of waste tire rubber and concluded that the reclaiming process influenced the thermal characteristics and the relation was confirmed by Horikx theory. Meanwhile, Shi et al. (2014) upheld the stability of the reclaimed waste tire through DSC examination. It was reported that the thermal glass transition temperature was slightly different from the raw natural rubber. Based on the previous investigation, the reclaimed waste tire rubber has a good thermal stability compared to the virgin rubber. The fact can be used as preliminary judgment for the durability of the 
prediction must be scientifically proven through the thermal analysis.

\section{Conclusion}

This study has investigated the prospect of using waste tire rubber and electronic waste for the MREs raw materials. The crumb rubber obtained from ground discarded tire has been utilized as the matrix carrier of MREs. The magnetizable particles have been prepared from electronic waste, i.e. magnetic core from CRTs monitor wastes. The mechanical milling, called high energy ball mill, has been performed for grinding the magnetic core waste resulting in micron-size and irregular-shape particles. The ground powders were confirmed as magnetite $\left(\mathrm{Fe}_{3} \mathrm{O}_{4}\right)$ through diffraction patterns and infrared spectrometry. Their magnetic properties were measured and confirmed to be potentially used as a replacement of the traded iron particles. The novel method for MREs preparation, namely HPHT technique, has been successfully used, in which the way of sample fabrication is considered to be simpler than other ways. The mechanism of simultaneous breaking and rebinding of sulfidic bound during vulcanization process has successfully been proven; it integrates bonding rubber and ferrous powders into a single piece.

The physicochemical properties of the as-prepared isotropic MREs have firstly been examined. Through infrared absorbance analysis of the activity of chemical compounding within MREs, it has been confirmed that the matrix carrier consists of several types of rubber. As it is apparent in microstructure graphs, the magnetite particles were capable of being thoroughly dispersed within the matrix. The magnetic properties have also been measured and the data could be further used to determine the permeability of the MREs. Mechanical testing in static and dynamic loads has been carefully carried out to examine the tunability of the samples as a response to the external magnetic fields. The results showed that the stresses of the MREs were always increasing with increase in the magnetic field and increase in weight fraction of magnetite powders. The influence of the magnetic field on the stress-strain relationship under static loading was indicated by the difference between initial curve gradient and that of the off-state condition. Meanwhile, the stress-strain relationship as a consequence of dynamic loading has formed hysteresis loop in which the impact of magnetization is shown by the wider area of the loops. In accordance with the evidence, the tunable mechanical properties of the waste based MREs are potential to be emerged in controllable stiffness vibration isolator. This innovation would be a wastes reclaiming strategy of rubber and electronic wastes to enhance the product value of reclaimed articles as well as an alternative novel way in managing hazardous materials.

\section{Acknowledgement}

This work has been supported by collaborative research between MJIIT-UTM (PRGS Grant No. 4L667 and RUG No. 06H06) as well as Universitas Sebelas Maret (Mandatory Research Grant 2015, No: 698/UN27/PN/2015).

\section{References}

1. Lo Presti, D. "Recycled tyre rubber modified bitumens for road asphalt mixtures: A literature review", Constr. Build. Mater., 49(8), pp. 63-81 (2013).

2. Trea, M. “Annual report 2012-2013”, ETRMA (2014).

3. Gajah Tunggal, P. "Annual report 2013", Jakarta (2013).

4. Vermeulen, I., Van Caneghem, J., Block, C., Baeyens, J. and Vandecasteele, C. "Automotive shredder residue (ASR): Reviewing its production from end-of-life vehicles (ELVs) and its recycling, energy or chemicals' valorisation", J. Hazard. Mater., 190, pp. 8-27 (2011).

5. Jimenez-Espadafor, F.J., Becerra Villanueva, Ja., García, M.T., Trujillo, E.C. and Blanco, A.M. "Optimal design of acoustic material from tire fluff", Mater. Des., 32, pp. 08-16 (2011).

6. Zebala, J., Ciepka, P., Reza, A. and Janczur, R. "Influence of rubber compound and tread pattern of retreaded tyres on vehicle active safety", Forensic Sci. Int., 167(1), pp. 73-80 (2007).

7. Kinoshita, T., Yamaguchi, K., Akita, S., Nii, S., Kawaizumi, F., and Takahashi, K. "Hydrometallurgical recovery of zinc from ashes of automobile tire wastes", Chemospher, 59(11), pp. 05-11 (2005).

8. Betancur, M., Martínez, J. and Murillo, R. "Production of activated carbon by waste tire thermochemical degradation with $\mathrm{CO}_{2}{ }^{\prime}$, J. Hazard. Mater., 168, pp. 882-7 (2009).

9. Saleh, T.A. and Gupta, V.K. "Processing methods, characteristics and adsorption behavior of tire derived carbons: A review", Adv. Colloid Interface Sci., 211, pp. 93-101 (2014).

10. Gupta, V.K., Ganjali, M.R., Nayak, A., Bhushan, B. and Agarwal, S. "Enhanced heavy metals removal and recovery by mesoporous adsorbent prepared from waste rubber tire", Chem. Eng. J., 197, pp. 330-42 (2012).

11. Pipilikaki, P., Katsioti, M., Papageorgiou, D., Fragoulis, D. and Chaniotakis, E. "Use of tire derived fuel in clinker burning", Cem. Concr. Compos., 27, pp. 843-7 (2005). 
12. Fernández, A.M., Barriocanal, C. and Alvarez, R. "Pyrolysis of a waste from the grinding of scrap tyres", J. Hazard. Mater., 203-204, pp. 236-43 (2012).

13. Jana, G.K. and Das, C.K. "Recycling natural rubber vulcanizates through mechanochemical devulcanization", Macromol. Res., 13, pp. 30-8 (2013).

14. Mui, E.L.K., Cheung, W.H. and McKay, G. "Tyre char preparation from waste tyre rubber for dye removal from effluents", J. Hazard. Mater., 175, pp. 151-8 (2010).

15. Shakya, P.R., Shrestha, P., Tamrakar, C.S. and Bhattarai, P.K. "Studies on potential emission of hazardous gases due to uncontrolled open-air burning of waste vehicle tyres and their possible impacts on the environment", Atmos. Environ., 42, pp. 6555-9 (2008).

16. Shi, J., Zou, H., Ding, L., Li, X., Jiang, K. and Chen, $\mathrm{T}$. "Continuous production of liquid reclaimed rubber from ground tire rubber and its application as reactive polymeric plasticizer", Polym. Degrad. Stab., 99, pp. 166-75 (2014).

17. Su, H.L., Yang, J., Ling, T.C., Ghataora, G.S. and Dirar, S. "Properties of concrete prepared with waste tyre rubber particles of uniform and varying sizes", $J$. Clean. Prod., 91, pp. 288-96 (2015).

18. Oliveira, J.R.M, Silva, H.M.R., Abreu, L.P. and Fernandes, S.R. "Use of a warm mix asphalt additive to reduce the production temperatures and to improve the performance of asphalt rubber mixtures", J. Clean. Prod., 41, pp. 15-22 (2013).

19. Rochman, F. "E-waste in Indonesia: The case of personal computers", Trop. Resour. Bull., 29, pp. 71-7 (2010).

20. Nnorom, I.C., Osibanjo, O, and Ogwuegbu, M.O.C. "Global disposal strategies for waste cathode ray tubes", Resour. Conserv. Recycl., 55, pp. 275-90 (2011).

21. Andarani, P. and Goto, N. "Potential e-waste generated from households in Indonesia using material flow analysis", J. Mater. Cycles. Waste. Manag., 16, pp. 306-20 (2013).

22. Tripathy, A.R., Morin, J.E., Williams, D.E., Eyles, S.J. and Farris, R.J. "A novel approach to improving the mechanical properties in recycled vulcanized natural rubber and its mechanism", Macromolecules, 35, pp. 4616-27 (2002).

23. Morin, J.E., Williams, D.E. and Farris, R.J. "A novel method to recycle scrap tires: High-pressure hightemperature sintering", Rubber Chem. Technol., 75, pp. $955-68$ (2002).

24. Morin, J.E. and Farris, R.J. "Recycling of $100 \%$ cross-linked rubber powder by high- temperature highpressure sintering", Lecture Note, University of Massachusetts (2000).
25. Bilgili, E., Dybek, A., Arastoopour, H. and Bernstein, B. "A new recycling technology: Compression molding of pulverized rubber waste in the absence of virgin rubber", J Elastomers Plast., 35, pp. 235-56 (2003).

26. Ginder, J.M., Nichols, M.E., Elie, L.D. and Tardiff, J.L. "Magnetorheological elastomers: Properties and applications", Conf. Smart Mater. Technol., 3675, Newport Beach, California, pp. 131-8 (1999).

27. Zhang, W., Gong, X.L., Xuan, S.H. and Jiang, W.Q. "Temperature-dependent mechanical properties and model of magnetorheological elastomers", Ind. Eng. Chem. Res., 50, pp. 6704-12 (2011).

28. Watson, J.R. "Method and apparatus for varying the stiffness of a suspension bushing", US005609353A (1997).

29. Ginder, J.M., Nichols, M.E., Elie, L.D. and Clark, S.M. "Controllable-stiffness components based on magnetorheological elastomers", Smart Struct. Integr. Syst., 3985, pp. 1-8 (2000).

30. Badolato, A.R. and Pawlowski, R.P. "Tunable slip yoke damper assembly", US006623364B2 (2003).

31. Rodenbeck, P.D. "Active magneto-rheological spring assemblies and vehicle suspension systems incorporating the same", US8210547B2 (2012).

32. Guomundsson, I., A Feasibility Study of Magnetorheological Elastomers for a Potential Application in Prosthetic Devices, School of Engineering and Natural Science (2011).

33. Rodenbeck, P.D. "Magneto-rheological elastomer wheel assemblies with dynamic tire pressure control", US8176958B2 (2012).

34. Du, G.T. and Chen, X.D. "MEMS magnetometer based on magnetorheological elastomer", Measurement, 45, pp. 54-8 (2012).

35. Ottaviani, R.A., Ulincy, J.C. and Golden, M.A. "Magnetorheological nanocomposite elastomer for releasable attachment applications", US6877193B2 (2005).

36. Nguyen, V.Q., Ahmed, A.S. and Ramanujan, R.V. "Morphing soft magnetic composites", Adv. Mater., 24, pp. 4041-54 (2012).

37. Thévenot, J., Oliveira, H., Sandre, O. and Lecommandoux, S. "Magnetic responsive polymer composite materials", Chem. Soc. Rev., 42, pp. 7099-116 (2013).

38. Ubaidillah, Sutrisno, J., Purwanto, A. and Mazlan, S.A. "Recent progress on magnetorheological solids: Materials, fabrication, testing, and applications", Adv. Eng. Mater., 17, pp. 563-97 (2015).

39. Wang, Y.L., Hu, Y., Deng, H.X., Gong, X.L., Zhang, P.Q. and Jiang, W.Q. "Magnetorheological elastomers based on isobutylene-isoprene rubber", Polym. Eng. Sci., 46, pp. 264-8 (2006). 
40. Ginder, J.M., Clark, S.M., Schlotter, W.F. and Nichols, M.E. "Magnetostrictive phenomena in magnetorheological elastomers", Int. J. Mod. Phys. B., 16, pp. 2412-8 (2002).

41. Wu, J.K, Gong, X.L., Chen, L., Xia, H.S. and Hu, Z.G. "Preparation and characterization of isotropic polyurethane magnetorheological elastomer through in situ polymerization", J. Appl. Polym. Sci., 114, pp. 901-10 (2009).

42. Li, Y.Z. and Ding, Z.H. "Research on magnetorheological elastomers air spring based NR/SBR rubber", Appl. Mech. Mater., 217-219, pp. 526-9 (2012).

43. Chen, L., Gong, X.L. and Li, WH. "Damping of magnetorheological elastomers", Chinese J. Chem. Phys., 21, pp. 581-5 (2008).

44. Zhu, J.T., Xu, Z.D. and Guo, Y.Q. "Experimental and modeling study on magnetorheological elastomers with different matrices", J. Mater. Civ. Eng., 25, pp. 176271 (2013).

45. Danas, K., Kankanala, S.V., and Triantafyllidis N. "Experiments and modeling of iron-particle-filled magnetorheological elastomers", J. Mech. Phys. Solids., 60, pp. 120-38 (2012).

46. Gong, X.L., Fan, Y.C., Xuan, S.H., Xu, Y.G. and Peng, C. "Control of the damping properties of magnetorheological elastomers by using polycaprolactone as a temperature-controlling component", J. Ind. Eng. Chem. Res., 51, pp. 6395-403 (2012).

47. Fan, Y.C., Gong, X.L., Xuan, S.H., Qin, L.J. and Li, X.F. "Effect of cross-link density of the matrix on the damping properties of magnetorheological elastomers", Ind. Eng. Chem. Res., 52, pp. 771-8 (2013).

48. Fan, Y.C., Gong, X.L., Jiang, W.Q., Zhang, W., Wei, B. and Li, W.H. "Effect of maleic anhydride on the damping property of magnetorheological elastomers", Smart Mater. Struct., 19, p. 055015 (2010).

49. Fan, Y.C., Gong, X.L., Xuan, S.H., Zhang, W., Zheng, J. and Jiang, W.Q. "Interfacial friction damping properties in magnetorheological elastomers", Smart Mater. Struct., 20, p. 035007 (2011).

50. Sun, T.L., Gong, X.L., Jiang, W.Q., Li, J.F., Xu, Z.B. and Li, W.H. "Study on the damping properties of magnetorheological elastomers based on cispolybutadiene rubber", Polym. Test., 27, pp. 520-6 (2008).

51. Lokander, M. and Stenberg, B. "Improving the magnetorheological effect in isotropic magnetorheological rubber materials", Polym. Test., 22, pp. 677-80 (2003).

52. Lokander, M. and Stenberg, B. "Performance of isotropic magnetorheological rubber materials", Polym. Test., 22, pp. 245-51 (2003).

53. Zaborski, M., Pietrasik, J. and Masћowski, M. "Elastomers containing fillers with magnetic properties", Solid State Phenom., 154, pp. 121-6 (2009).
54. Maslowski, M. and Zaborski, M. "Smart materials based on magnetorheological composites", Mater. Sci. Forum., 714, pp. 167-73 (2012).

55. Liao, G.J., Gong, X.L., Xuan, S.H., Guo, C.Y. and Zong, L.H. "Magnetic-field-induced normal force of magnetorheological elastomer under compression status", Ind. Eng. Chem. Res., 51, pp. 3322-8 (2012).

56. Fuchs, A., Sutrisno, J., Gordaninejad, F., Caglar, M.B. and Yanming, L. "Surface polymerization of iron particles for magnetorheological elastomers", J. Appl. Polym. Sci., 117, pp. 934-42 (2010).

57. Gong, X.L., Chen, L. and Li, J.F. "Study of utilizable magnetorheological elastomers", Int. J. Mod. Phys., 21, pp. 4875-82 (2007).

58. Lerner, A.M.A. and Cunefare, K.A. "Adaptable vibration absorber employing a magnetorheological elastomer with variable gap length and methods and systems therefor", US7102474B2 (2006).

59. Yang, R.B. and Liang, W.F. "Microwave properties of high-aspect-ratio carbonyl iron/epoxy absorbers", $J$ Appl. Phys., 109, p. 07A311 (2011).

60. Huang, X., Mohla, A., Hong, W., Bastawros, A.F. and Feng, X.Q. "Magnetorheological brush - a soft structure with highly tuneable stiffness", Soft Matter, 10, pp. 1537-43 (2014).

61. Krolewicz, M., Przybylski, M., Lewandowski, D. and Kaleta, J. "Manufacture and testing of anisotropic magnetorheological elastomers", Proc. 11th Youth Symp. Exp. Solid Mech., Brasov, Romania (2012).

62. Böse, H. and Röder, R. "Magnetorheological elastomers with high variability of their mechanical properties", J. Phys. Conf. Ser., 149, p. 012090 (2009).

63. Sorrentino, L., Aurilia, M., Forte, G. and Iannace, S. "Composite polymeric foams produced by using magnetic field", Adv. Sci. Technol., 54, pp. 123-6 (2008).

64. Li, W.H. and Nakano, M. "Fabrication and characterization of PDMS based magnetorheological elastomers", Smart Mater. Struct., 22, p. 055035 (2013).

65. Zhang, X.Z. and Li, W.H. "Investigation of bimodal particles based magnetorheological elastomers", Adv. Mater. Res., 32, pp. 165-8 (2008).

66. Tobolsky, A.V. "Polymeric sulfur and related polymers", J. Polym. Sci. Part C., 12, pp. 71-8 (1966).

67. De Carvalho, J.F., de Medeiros, S.N., Morales, M.A., Dantas, A.L. and Carriço, A.S. "Synthesis of magnetite nanoparticles by high energy ball milling", Appl. Surf. Sci., 275, pp. 84-7 (2013).

68. Can, M.M., Ozcan, S., Ceylan, A. and Firat, T. "Effect of milling time on the synthesis of magnetite nanoparticles by wet milling", Mater. Sci. Eng. B., 172, pp. 72-5 (2010). 
69. Rahman, O., Mohapatra, S.C. and Ahmad, S. " $\mathrm{Fe}_{3} \mathrm{O}_{4}$ inverse spinal super paramagnetic nanoparticles", Mater. Chem. Phys., 132, pp. 196-202 (2012).

70. Morel, M., Martínez, F. and Mosquera, E. "Synthesis and characterization of magnetite nanoparticles from mineral magnetite", J. Magn. Magn. Mater., 343, pp. 76-81 (2013).

71. Zhao, F., Zhang, B. and Feng, L. "Preparation and magnetic properties of magnetite nanoparticles", Mater. Lett., 68, pp. 112-4 (2012).

72. Charles J. "Spectroscopic, dielectric, thermal and hardness studies on uncured and cured hydrogenated nitrile butadiene rubber and chlorosulphonated monomer", Int. Journl Chem. Tech. Res., 6, pp. 1081-90 (2014).

73. Litvinow, V.M. and De, P.P. "Spectroscopy of rubber and rubbery materials", Rapra Technology Limited (2002).

74. Zanchet, A., Carli, L.N., Giovanela, M., Brandalise, R.N. and Crespo, J.S. "Use of styrene butadiene rubber industrial waste devulcanized by microwave in rubber composites for automotive application", Mater. Des., 39, pp. 437-43 (2012).

75. Koo, J.H., Khan, F., Jang, D.D. and Jung, H.J. "Dynamic characterization and modeling of magnetorheological elastomers under compressive loadings", Smart. Mater. Struct., 19, p. 117002 (2010).

76. Kallio, M., Lindroos, T., Aalto, S., Järvinen, E., Kärnä, T. and Meinander, T. "Dynamic compression testing of a tunable spring element consisting of a magnetorheological elastomer", Smart Mater. Struct., 16, pp. 506-14 (2007).

77. Zając, P., Kaleta, J., Lewandowski, D. and Gasperowicz, A. "Isotropic magnetorheological elastomers with thermoplastic matrices: structure, damping properties and testing", Smart Mater. Struct., 19, p. 045014 (2010).

78. Chen, L., Gong, X.L. and Li, W.H. "Effect of carbon black on the mechanical performances of magnetorheological elastomers", Polym. Test., 27, pp. 340-5 (2008).

79. Xu, Y.G., Gong, X.L., Xuan, S.H., Zhang, W. and Fan, Y.C. "A high-performance magnetorheological material: Preparation, characterization and magneticmechanic coupling properties", Soft Matter., 7, p. 5246 (2011).

80. Xu, Y.G., Gong, X.L., Xuan, S.H., Li, X.F., Qin, L.J. and Jiang, W.Q. "Creep and recovery behaviors of magnetorheological plastomer and its magneticdependent properties", Soft Matter., 8, p. 8483 (2012).

81. Ivaneyko, D., Toshchevikov, V., Saphiannikova, M. and Heinrich, G. "Magnetorheological elastomers", Encycl. Polym. Nanomater., pp. 1-8 (2014).

82. Zhang, W., Gong, X.L., Jiang, W.Q. and Fan, Y.C.
"Investigation of the durability of anisotropic magnetorheological elastomers based on mixed rubber", Smart Mater. Struct., 19, p. 085008 (2010).

83. De, D., Das, A., Dey, B., Debnath, S.C. and Roy, B.C. "Reclaiming of ground rubber tire (GRT) by a novel reclaiming agent", Eur. Polym. J., 42, pp. 91727 (2006).

84. Formela, K., Cysewska, M. and Haponiuk, J. "The influence of screw configuration and screw speed of co-rotating twin screw extruder on the properties of products obtained by thermomechanical reclaiming of ground tire rubber", Polimery, 59, pp. 170-7 (2014).

85. Shi, J.W., Zou, H., Ding, L.L., Li, X.L., Jiang, K. and Chen, T. "Continuous production of liquid reclaimed rubber from ground tire rubber and its application as reactive polymeric plasticizer", Polym. Degrad. Stab., 99, pp. 166-75 (2014).

\section{Biographies}

Ubaidillah is currently $\mathrm{PhD}$ student in MalaysiaJapan International Institute of Technology (MJIIT), Universiti Teknologi Malaysia (UTM). He earned his master's degree from Universiti Teknikal Malaysia (UTeM) in 2010. He is also a staff member of Mechanical Engineering Department, Faculty of Engineering, Universitas Sebelas Maret. His PhD research focuses on the synthesis, characterization, physical and mechanical properties evaluation, and development of magnetorheological elastomers. He has worked in many areas of magnetorheological devices (MR damper, MR brake, and MR engine mounting) including synthesize, device design, characterization, and related applications.

Saiful Amri Mazlan is a registered Professional Engineer with Board of Engineers Malaysia. He holds a doctorate degree from Dublin City University, Ireland. He is currently a senior Lecturer at MJIIT-UTM. His research is primarily in the area of magnetorheological (MR) fluids, where this material undergoes significant responses, leading to consequent rheological changes upon the influence of an external field. The same phenomenon also happens in MR Elastomer, where both materials can offer tremendous opportunities for variable stiffness devices. He has managed to publish his research works at several international journals and conference proceedings.

Joko Sutrisno, $\mathrm{PhD}$, is currently an adjunct faculty member in Chemical Engineering Department, University of Surabaya (UBAYA), Indonesia. He received his $\mathrm{PhD}$ in Chemical Engineering in 2011 from University of Nevada Reno (UNR). He worked as a Teaching Assistant and Research Assistant, involved in many areas of polymeric materials research, sponsored by 
the Department of Defense (DoD) and National Science Foundation (NSF). His experience in research includes: synthesis and development of proton exchange membranes for fuel cells, direct methanol fuel cells, alkaline fuel cells, development of magneto-rheological polymer gels, fluid and elastomers, and development of magneto-rheological fluid for cancer therapy.

Iwan Yahya works as Associate Professor in the Department of Physics, Faculty of Mathematics and Sciences, Universitas Sebelas Maret. He leads Iwany Acoustic Research Group. He has tremendous experience in acoustic materials, noise control, and functional material development.
Harjana is currently Associate Professor in the Department of Physics, Faculty of Mathematics and Sciences, Universitas Sebelas Maret. He obtained his PhD degree in 2002 from State University of New York at Albany. He manages his research area on material physics, especially for vibration fields.

Fitrian Imaduddin received his BEng in Engineering Physics from ITS, Indonesia; MSc in Mechanical Engineering from UTeM, Malaysia; and PhD in Magnetorheological (MR) Actuator from Universiti Teknologi Malaysia (UTM). His research interests include design, modeling, and control of smart actuators. He is currently attached with UTM, Kuala Lumpur campus. 